\title{
Economic Impact Evaluation and Household Adaptation to Extreme Weather Events in the Municipality of Bay, Laguna, Philippines
}

\author{
Joela Mizchelle A. Dela Vega ${ }^{1}$, Joshua G. Jomao-as ${ }^{1,3}$, Francis Jhun T. Macalam ${ }^{1,2}$ \\ Kevin John R. Lino ${ }^{1}$, \& Merry Joy R. Ilagan ${ }^{1}$ \\ School of Environmental Science and Management ${ }^{l}$, University of the Philippines Los Baños, \\ College, Los Baños, Laguna, Philippines \\ Department of Environmental Science and Technology ${ }^{2}$, College of Science and Mathematics, \\ University of Science and Technology of Southern Philippines \\ CM. Recto Avenue, Lapasan, Cagayan de Oro City, Philippines \\ Institute of Biological Sciences ${ }^{3}$, University of the Philippines Los Baños \\ College, Los Baños, Laguna, Philippines
}

\begin{abstract}
Bay is one of the municipalities in the province of Laguna that is situated along the coast of Laguna de Bay, and is particularly vulnerable to natural disasters including typhoons and flash floods. Among these, Barangay Dila, San Isidro, and Tagumpay located in low-lying elevation of the Municipality of Bay were not spared by the impacts caused by the disaster. Hence, the study site was conducted in these flood-prone areas of the Municipality. In this study, it highlights the impacts and adaptation of the household to extreme weather events. Specifically, the study aims to identify, quantify, and monetized (whenever possible) the household's impacts of extreme floods and typhoons; described the adaptation actions undertaken by the households; and to evaluate the factors that significantly affect the choice of adaptation activities. The data used in this study was collected through a survey of 90 households. In selecting the household, random sampling was employed using the data that was acquired from the municipality. The selected household heads were interviewed using the structured sample questionnaire. Probit regression was employed to test the significant factors of the choices of adaptation activities of the household. The study revealed that the impacts of extreme weather events on the households of Bay, Laguna could be considered to be ranging from moderate to severe cases depending on the geographical location of the households. Also, households of Bay, Laguna considers the height of flood and distance from bodies of water as significant factors for undertaking adaptation actions.
\end{abstract}

Keywords - Natural hazards, Flood, Household adaptation, Key Informant Interview, Disaster Risk Reduction Management, Probit regression

\section{INTRODUCTION}

The Philippines falls in Southeast Asia. It consists of three large islands: Luzon, Visayas , and Mindanao. This is located along the Pacific typhoon belt (Asian Disaster Reduction Center, 2017), which is why an average of twenty ( 20) typhoons are encountered each year, five of which are devastating. Based on the World Risk Index (2016), the Philippines ranks third in Disaster Risk (index value: 27.98) next from the first and second ranked countries of Vanuatu and Tonga, respectively. Thus, the country is one of the utmost risks being hit by different calamities or an extreme natural event such as typhoons and flooding.

\section{Climate Change in the Philippines}

The Philippines ranked first as the most affected country by climate change according to the 2015 Global Climate Risk Index. The Philippines is situated in the West Pacific Ocean, surrounded by naturally warm 
waters. Such warm waters can get even hotter as the sea-surface temperature rises. In addition, with the impact of climate change, it will increase the surface temperature of the ocean over time, and more heat is released into the atmosphere, contributing to frequent and stronger storms (Eckstein D. et al., 2015). Because of its economic status and geographic position, the Philippines is one of the countries that is very vulnerable to climate change effects such as; temperature increases, sea-level rises, and extreme weather disruptions such as typhoons and floods. The Philippines is known as a natural disaster hot spot, 50.3 percent of its total area and 81.3 percent of its population are vulnerable to natural disasters. Nearly 85.2 per cent of its annual US $\$ 86$ billion GDP is at risk because it is put in areas of risk. Specific disasters have affected about three million Filipinos annually since 2000 (DILG, 2011).

According to a study conducted by Eckstein D. Et al . (2015), the effects of climate change, such as extreme weather events, damaged property and thousands of people loss of lives of thousands of people. The impacts have resulted in ecological destruction and biodiversity loss that have a negative effect on Philippine society, economy and climate. The estimated annual loss from flooding in the country was about 24,424,082,685.00 pesos, according to the Philippine Disaster and Risk Profile last 2014.

\section{DESCRIPTION OF THE STUDY SITE}

\section{Bay, Laguna}

Bay is one of the municipalities in Laguna Province that is located along the Laguna de Bay shore and is highly vulnerable to natural hazards such as floods and flash floods. There are three ( 3 ) barangays that are highly susceptible to flooding (Dila, San Isidro, and Tagumpay) while there are four (4) barangays that are prone to flash flooding due to the large rivers overflowing. Other hazards in some crowded areas include raininduced landslide (upland barangays), ground shaking, and fire hazard (MDRRM Plan, 2017).

Typhoon Glenda hit the country in July 2014, numerous barangays in the town of Bay have flooded heavily, resulting in great damage to the residents' lives and property. Many barangays had been sunk into deep floodwaters.

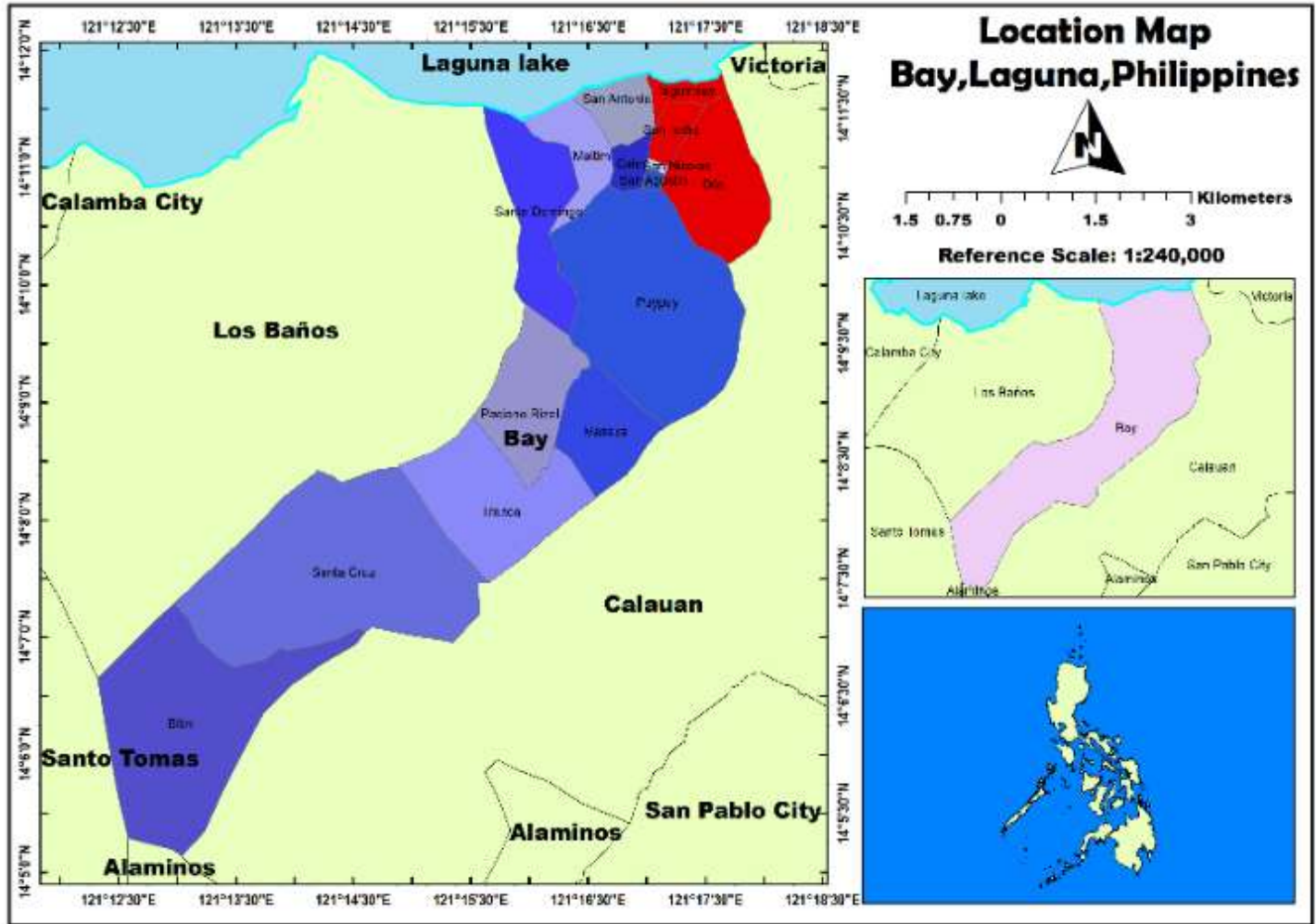

Figure 1. Location Map of Bay, Laguna, Philippines 


\section{OBJECTIVES OF THE STUDY}

The study's general purpose is to examine the impacts of extreme weather events on the households. The research directly aimed at;

1. To recognize, measure and monetize the impacts of severe floods and typhoons on households (wherever possible);

2. To identify the households taking the adaptation actions;

3. Determine factors which have a major impact on the choice of adaptation activities;

4. Drawing up a realistic suggestion based on study findings

\section{IV.CONCEPTUAL FRAMEWORK}

Extreme weather (flooding and typhoons) affects resilience by destroying livelihoods and property, income loss, and health and educational impacts. On the other hand, the household 's choice of adaptation action can also affect resilience through group adaptation. Thus interventions by the government unit may either stimulate or limit change practices.

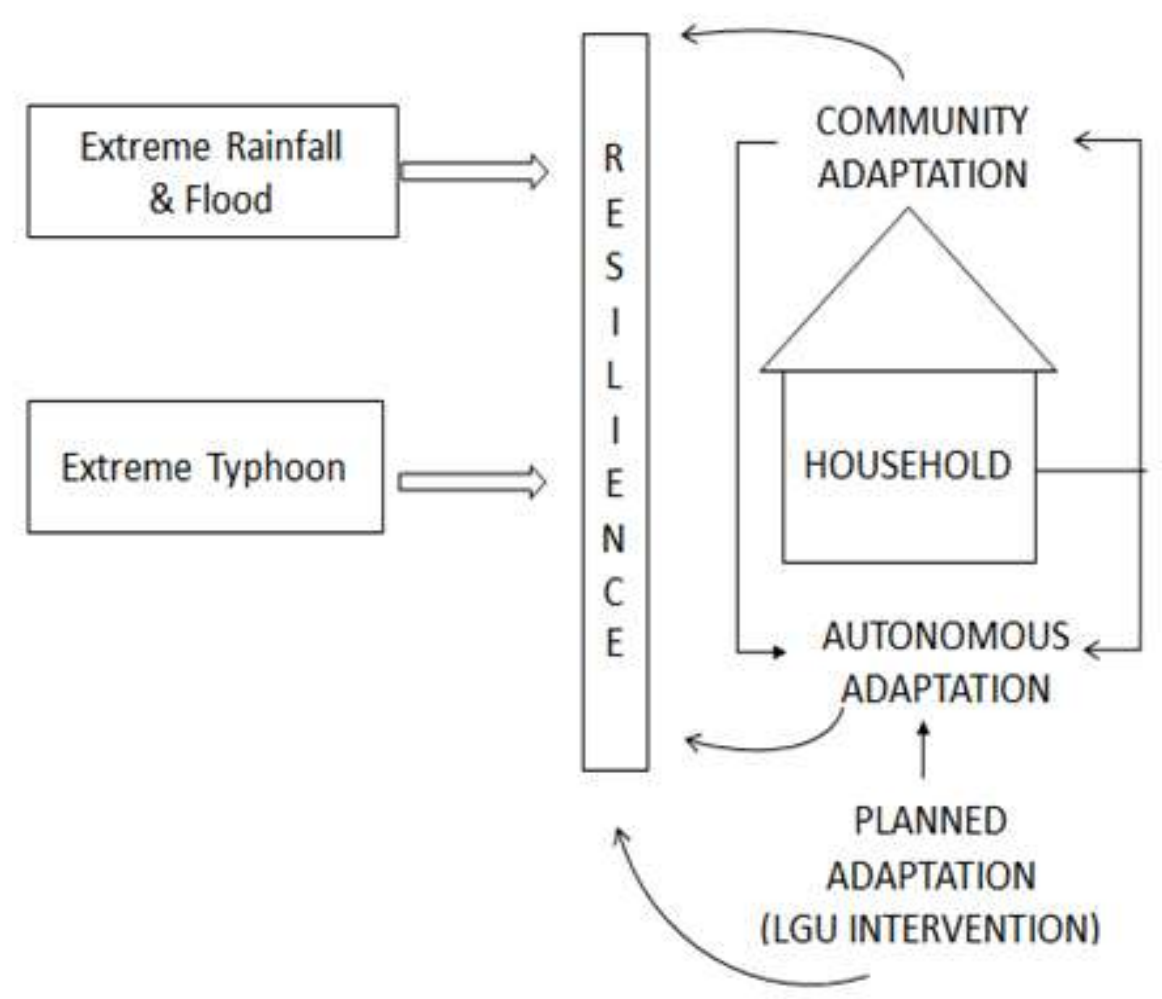

Figure 2. Showing the Conceptual Framework of the Study Adopted from the study of Professor Jamie Kim Arias, et.al ((2016), Impacts of and the Adaptation to Extreme Weather Events: An Intrahousehold Perspective 


\section{ANALYTICAL FRAMEWORK}

\section{Impact Analysis}

The impacts of households reported in this study which includes the impacts of household property, livelihood, employment, health, and education were evaluated using the indicators as well as the methods of valuation summarized in Table 1.

TABLE 1. Summary of methods used in the analysis of impacts

\begin{tabular}{|c|l|l|}
\hline $\begin{array}{c}\text { Impact } \\
\text { pamage to } \\
\text { property }\end{array}$ & $\begin{array}{l}\text { Measures/Indicators } \\
\text { Damage/loss of house } \\
\text { Damage/loss of belongings } \\
\text { (household appliances, clothes, } \\
\text { furniture, electronic devices) } \\
\text { Damage/loss of vehicles }\end{array}$ & $\begin{array}{l}\text { Valuation Method } \\
\text { salvageable) }\end{array}$ \\
\hline $\begin{array}{c}\text { Impacts on } \\
\text { livelihoods }\end{array}$ & $\begin{array}{l}\text { Damage/loss of fishing boats } \\
\text { Damage/loss of the farm, } \\
\text { equipment/machinery }\end{array}$ & $\begin{array}{l}\text { Cost of repairs (if } \\
\text { salvageable) } \\
\text { Replacement cost (if } \\
\text { non-salvageable) }\end{array}$ \\
\hline Loss of income & $\begin{array}{l}\text { Work loss days } \\
\text { Loss of income }\end{array}$ & $\begin{array}{l}\text { Average monthly } \\
\text { income } \\
\text { Reported income losses }\end{array}$ \\
\hline Impacts on health & $\begin{array}{l}\text { Dengue } \\
\text { Diarrhea } \\
\text { Injuries } \\
\text { Skin infections } \\
\text { Leptospirosis }\end{array}$ & $\begin{array}{l}\text { Cost of illness } \\
\text { (hospitalization and } \\
\text { medication cost, } \\
\text { foregone income due to } \\
\text { work-loss days is already } \\
\text { captured in income } \\
\text { losses) }\end{array}$ \\
\hline Education & Lost school days due to absences & \\
\hline
\end{tabular}

The respondent chooses to undertake preparations if U_1> U_0. Assuming that U_1iand U_0i are normally distributed, then U_1i- U_0i is normally distributed, and the expression below can be evaluated. This can be computed using the maximum likelihood framework through Stata.

$$
\left.\mathrm{P}\left(\mathrm{U} \_1 \mathrm{i}>\mathrm{U} \_0 \mathrm{i}\right)=\mathrm{P}\left[\mathrm{U} \_1 \mathrm{i}-\mathrm{U} \_0 \mathrm{i}>-\gamma\left(\mathrm{Z} \_1 \mathrm{i}-\mathrm{Z} \_0 \mathrm{i}\right)-\mathrm{i}\left(\mathrm{B} \_1-\mathrm{B} \_0\right)\right] \quad \text { (equation } 1\right)
$$

\section{MATERIALS AND METHODS}

The whole data collection process was performed step by step. It was split into five phases to arrive at the specific details required for the analysis. This paper documented the selection of general study sites, key environmental issues, unique study location, sample size generation, and household surveys. Figure 2 below shows the research phase flow for the data collection and sampling system 


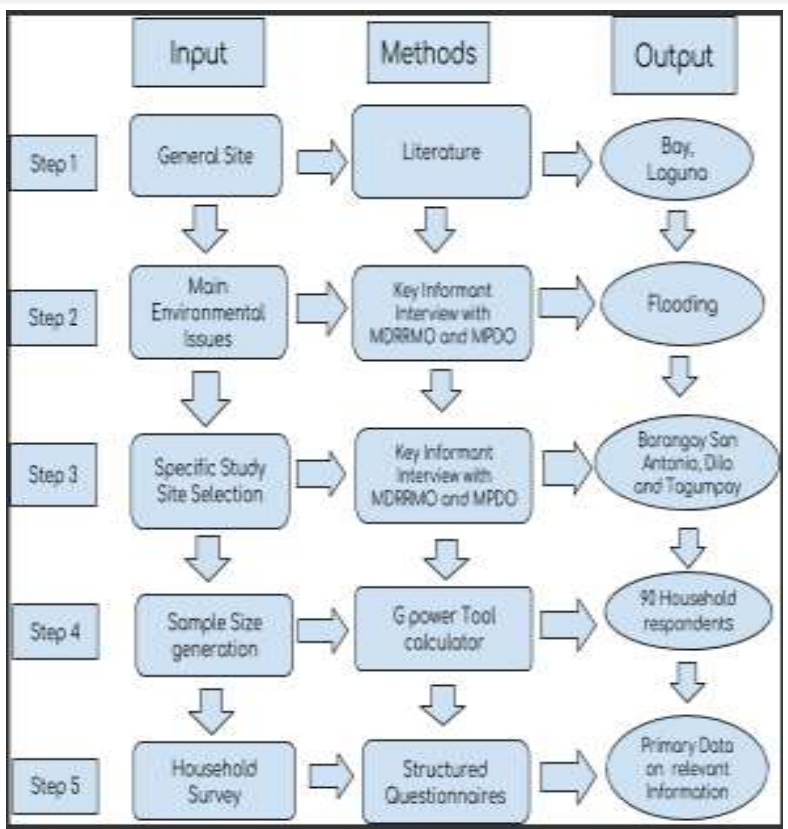

Figure 3. Data Collection and Sampling Method Process flow

\section{Household surveys}

The data used in this analysis were obtained from a sample of 90 households. The sample size was created as a representative household sample, using $\mathrm{G}$ power tools software. Random sampling was used in choosing the household, using the data obtained from the municipality. The head of each household was interviewed either male or female. Survey questionnaires were used to collect the following information: (1) Household characteristics (2) Experiences / Actions prior to and during extreme weather events (3) Effects of extreme weather events (4) Rehabilitation activities and opinions regarding interventions.

\section{Regression Analysis}

The collected information through the survey was employed in a probit regression using STATA 14 with the statistical equation of:

$$
\mathrm{ADAPT}=\mathrm{B} \_0+\mathrm{B} \_1 \mathrm{INC}+\mathrm{B} \_2 \mathrm{HSE}+\mathrm{B} \_3 \mathrm{COMM} \text { 『+ B } \rrbracket \_4 \mathrm{DIS}+\mathrm{B} \_5 \mathrm{HIN} \quad \text { (equation 2.) }
$$

where:

ADAPT, which is a dummy variable for if the household undertook any adaptation action (in this case, done improvement in their house);

INC, which is the household income divided by the household size;

HSE, which is a dummy variable for if the dwelling units are built primarily of permanent materials;

COMM, which is a dummy variable for the presence of community-level adaptation;

DIS, which is the distance of the house to the nearest body of water (in meters);

HIN, which is the highest recorded height of flood inside the house (in inches).

\section{RESULTS AND DISCUSSION}

The municipality of Bay, Laguna is, as predicted, highly vulnerable to severe weather events like floods and typhoons. Furthermore, the influence of typhoons and floods on Bay 's households, Laguna used the Typhoon Glenda effects as a reference point in 2014. In particular, impacts have been reported on property damage, housing, schooling, health and loss of income. 


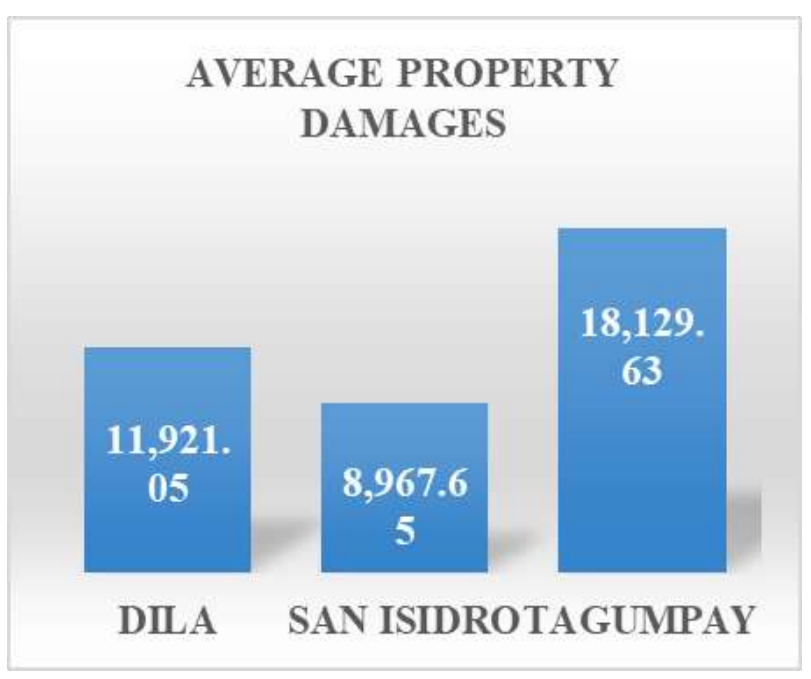

Figure 4. Average Property Damages for each barangay

For the property damages, households from Barangay Tagumpay has the most number of losses to property damages, on the average, at P18,129.63.00. This is mainly due to the geographical location of the barangay which is on the boundaries of Laguna Lake.

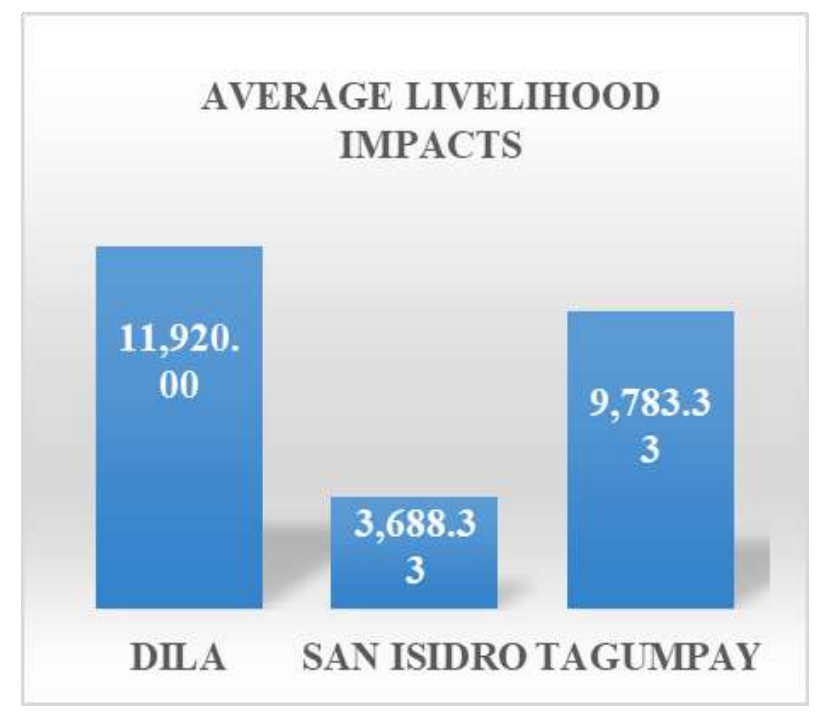

Figure 5. Average Livelihood Impacts for each barangay

In terms of the impacts on livelihood, Barangay Dila has the highest recorded losses on livelihood. One reason for this is the fact that most households of Barangay Dila have either business on the market or farmers. Moreover, Barangay Tagumpay has an average of P9,783.33 livelihood damages in the event of extreme weather events. This damages to livelihood are primarily due to the nature of the work of households in Bay, Laguna which is either on the field of fishing or farming. 


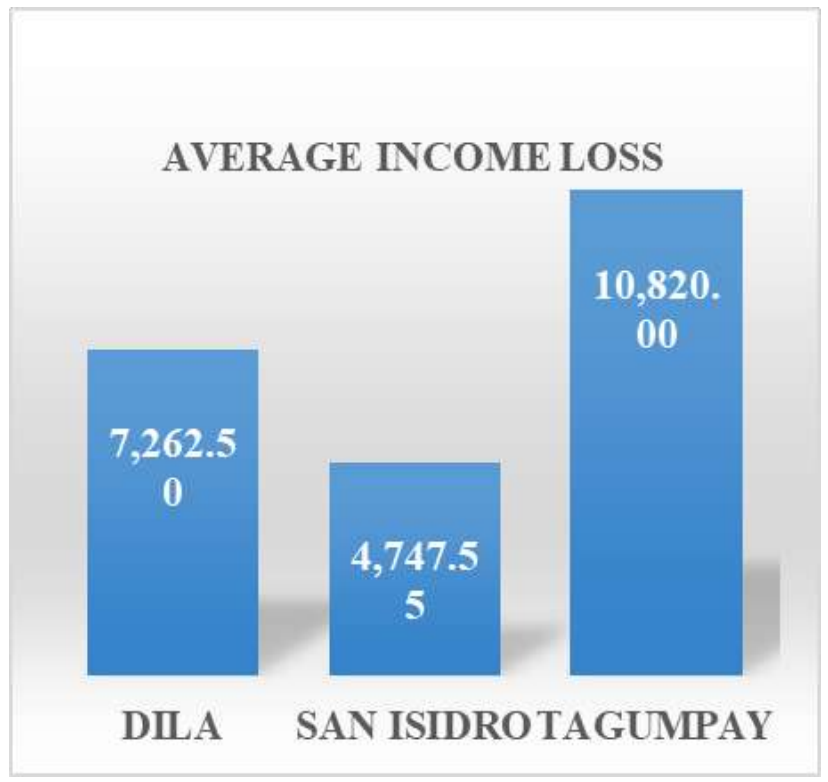

Figure 6. Average Income Loss for each barangay

Consequently, Barangay Tagumpay has the highest recorded income loss for the same reason that the nature of the source of income of most of the households in this barangay, which is fishing, is highly affected by extreme weather events.

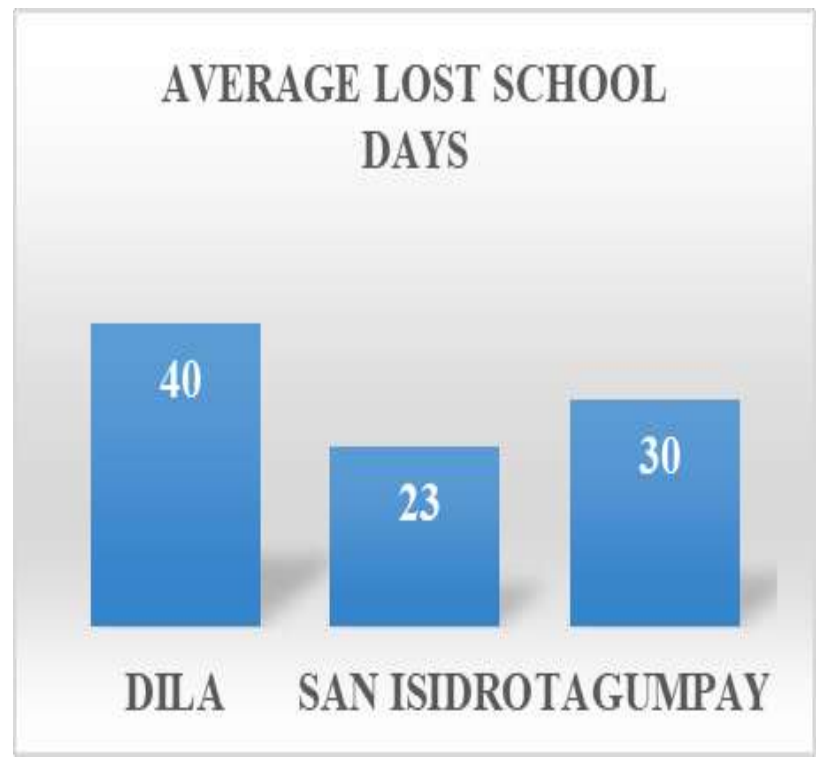

Figure 7. Average Lost School Days for each barangay

On the impacts of education, the average lost school days for each barangay was used as an indicator to measure how extreme weather events affect education. Although the average number of school day's loss for each barangay was relatively close, Barangay Dila has the highest number of lost school days which is basically because the schools in their barangay are used as an evacuation center. The use of school buildings as evacuation centers usually imposes certain issues of cleanliness and order to these premises resulting in the schools not being ready for the students instantly after extreme weather events. 


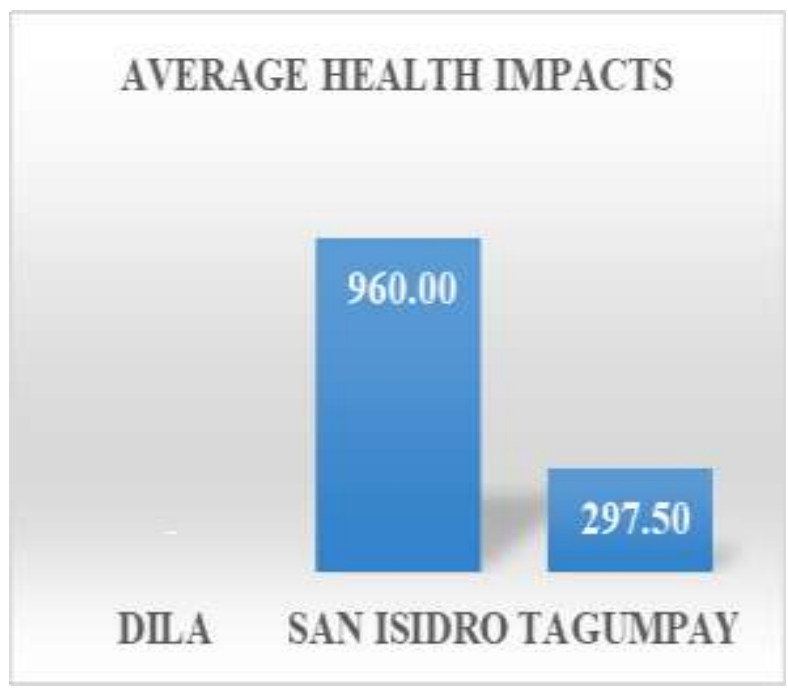

Figure 8. Average Health Impacts for each barangay

Lastly, health impacts, using the cost of illness as a valuation method, were also measured and quantified for each barangay. As shown by Figure 9, there is a low number of cases of recorded illness during the Typhoon Glenda therefore minimal impact for each barangay on health costs. However, the zero cost for Barangay Dila doesn't mean that no recorded person caught ill during Typhoon Glenda. This could also pose that there are no expenses incurred for the households as free medicines and check-ups are available in community clinics.

Meanwhile, results generated from the use of probit regression to identify the factors which significantly affect the decision of households to undertake adaptation actions are shown in Table 3 . Out of the five explanatory variables used, only the distance of the households from the body of water and the highest recorded height of flood inside the house was significant at $\alpha=1 \%$. This means that households significantly take into consideration these two factors on deciding whether to undertake adaptation action (such as doing improvement in their house) or not.

TABLE 2. Probit regression results on the determinants of proactive adaptation

\begin{tabular}{|l|c|c|}
\hline Parameter & Coeff. & $\mathbf{P}>|\mathbf{z}|$ \\
\hline INC & -0.000034 & 0.214 \\
\hline HSE & -0.3043017 & 0.442 \\
\hline COMM & 0.1539125 & 0.733 \\
\hline DIS & $-0.3769542 * * *$ & 0.004 \\
\hline HIN & $0.0167539 * * *$ & 0.001 \\
\hline Prob $>\mathrm{chi}^{2}$ & \multicolumn{2}{|c|}{0.0000} \\
\hline Pseudo ${ }^{2}$ & 0.2700 \\
\hline
\end{tabular}

Note: $* * *$ is significant at the $1 \%$ level.

\section{CONCLUSIONS AND RECOMMENDATIONS}

Impacts of Extreme Weather Events to the Households of Bay, Laguna could be range from moderate to severe cases depending on the geographical location of the households. Moreover, a household of Bay, Laguna considers Height of Flood and Distance from Bodies of Water as significant factors for undertaking adaptation actions. For further studies, an increasing number of sample sizes should be done because a higher sample size will provide more accuracy that will reflect the population closely around the population mean. 
This study analyzed and documented the experiences of the household in the three barangays of Bay, Laguna namely San Isidro, Tagumpay, and Dila during the typhoon Glenda in 2014 and flooding incidents in their respective barangays. According to the result of the study, training, and seminars like prevention and preparedness activities, knowledge building, and awareness programs regarding the disaster preparation of the constituents of Bay, Laguna should be addressed. Also, risk assessment and early warning systems should be in place in different barangays for them to be alert in possible extreme weather events.

Each barangay should have supplies, materials (first aid kit), equipment, and vehicle (if possible) for quick response to the affected "purok/sitio" in case of typhoons and floods.

\section{ACKNOWLEDGMENT}

The researcher team would like to thank Mr. Dante V. Vergara for guiding and sharing his expertise to accomplished the study.

\section{REFERENCES}

[1] Arias, J.K.B.; J.A. Arapoc; \& J.J.P. Mediodia (2016). Impacts of and Adaptation to Extreme Weather Events: An Intra-Household Perspective. EEPSEA Research Report No. 2016-RR2. Economy and Environment Program for Southeast Asia, Laguna, Philippines.

[2] Bantayan N. (2014). Flood risk analysis for the Municipality of Bay, Laguna, Philippines. Asia Life Sciences. Retrieved on November 23, 2017

[3] Department of Interior and Local Government. (2011).Climate Change in the Philippines. DOST-PAGASA. Retrieved on November 20, 2017, from http://dilg.gov.ph/PDF_File/reports_resources/DILG-Resources-2012130-2ef223f591.pdf

[4] Department of Interior and Local Government. (2011).Climate Change in the Philippines. DOST-PAGASA. Retrieved on November 20, 2017, from http://dilg.gov.ph/PDF_File/reports_resources/DILG-Resources-2012130-2ef223f591.pdf

[5] Eckstein D., Hagen U., Junghans L., Kerestan C., \& Kreft S. (2015). GLOBAL CLIMATE RISK INDEX 2015: Who Suffers Most From Extreme Weather Events? Weather-related Loss Events in 2013 and 1994 to 2013. Germanwatch e.V. Retrieved on November 20, 2017, from https://germanwatch.org/en/download/10333.pdf

[6] Information on the Disaster Risk Reduction of the Member Countries-Philippines. Asian Disaster Reduction Center (ADRC). Retrieved on November 22, 2017, from http://www.adrc.asia/nationinformation.php?NationCode=608

[7] Inquirer.net. (2013). The Deadliest Natural Disaster in the Philippines, published on October 15, 2013, at 05:37 PM. Retrieved on November 23, 2017, from http://newsinfo.inquirer.net/507589/the-deadliest-natural-disasters-in-the-philippines

[8] Municipality of Bay. (2017). Municipal Disaster Risk Reduction Management (MDRRM) Plan.

[9] World Risk Index. 2015. Integrated Research on Disaster Risk (IRDR). Retrieved on November 23, 2017, from http://www.irdrinternational.org/2016/03/01/word-risk-index/ 